\title{
Highly Efficient Photo-Induced Cathodic Protection of 403SS by the All-Solid-State Z-Scheme ZnS-CdS-Ag@ $\mathrm{TiO}_{2}$ Nanoheterojunctions
}

\author{
Yanfeng Zhu*, Yuanwei Liu, Zhongnian Yang \\ Department of Chemical Engineering and Safety, Binzhou University, Binzhou, Shandong 256603, PR \\ China \\ *E-mail: yanfengzhu2014@163.com
}

doi: $10.20964 / 2019.01 .74$

Received: 10 October 2018 / Accepted: 9 November 2018 / Published: 30 November 2018

\begin{abstract}
An all-solid-state Z-scheme $\mathrm{ZnS}-\mathrm{CdS}-\mathrm{Ag} @ \mathrm{TiO}_{2}$ nanoheterojunction was successfully fabricated to reduce the recombination rate of photogenerated charge carriers and enhance the photocathodic protection efficiency for 403 stainless steel (SS). The results showed that the photoabsorption spectrum of the composite film was expanded into the visible light region and that the photocurrent density was remarkably enhanced. Under irradiation conditions, the composite film as a photoanode could exhibit a striking photocathodic protection performance for the 403SS. These results demonstrated that the Zscheme system is beneficial for improving the separation of photogenerated charge carriers, thus achieving a highly enhanced photocathodic protection performance.
\end{abstract}

Keywords: Photocathodic protection; Titanium; Stainless steel; EIS; Oxide coatings

\section{$\underline{\text { FULL TEXT }}$}

(C) 2019 The Authors. Published by ESG (www.electrochemsci.org). This article is an open access article distributed under the terms and conditions of the Creative Commons Attribution license (http://creativecommons.org/licenses/by/4.0/). 